\title{
David Oliver: Confidentiality on the wards-regulations and reality
}

\section{David Oliver consultant in geriatrics and acute general medicine}

Berkshire

In January the General Medical Council published its updated guidance on confidentiality and handling patient information. ${ }^{1}$ It's a comprehensive manual highlighting doctors' duties, backed by ethical frameworks, relevant law, good practice, and regulatory standards for most scenarios. ${ }^{23}$

For jobbing clinicians, the most relevant section is "Disclosure to support the care of an individual patient"-for patients who can consent and, crucially for modern hospital populations, for those who lack this capacity. The new guidance clearly states that we must act within the law and seek legal guidance if uncertain.

Some transgressions are obvious, ${ }^{2}$ such as gossiping about patients in lifts or cafes, leaving printed patient lists around, or disclosing information against a patient's express wishes. But in other areas, confidentiality is not so clear cut.

Perfect confidentiality can never be rigidly maintained in a hospital: ward rounds would never end, and quality of care and communication would be compromised. Both the GMC guidance and the Care Quality Commission inspection standards ${ }^{4}$ emphasise the need for timely and accessible information to support good care.

Bedside conversations can benefit care, but closed curtains aren't soundproof

Patients' names, preferred names, instructions about moving and handling, and diet are often above the bed, with drug charts and other charts in folders nearby. Of course, patients' notes can be kept in locked trolleys, but as they are used by multiple members of the team they may end up being carried around the ward.

Ward rounds are sometimes conducted in areas that are not private. We can do much of our talking outside the patient bays, but visitors or other patients in the corridor or side rooms might overhear us instead. Visitors wanting updates sometimes approach clinical teams while they are talking.
The welcome move to unrestricted visiting and involvement of carers ${ }^{5}$ means a greater risk of confidentiality breaches. We don't have the time to clear visitors from every area or take them to private rooms for a chat when they are already at the bedside. Moreover, bedside conversations can greatly benefit care and communication, but closed curtains aren't soundproof.

Then there is email. Patients' relatives are increasingly emailing doctors for updates and answers to questions. NHS internet servers are not secure enough for sending confidential communication. But is replying over a potentially insecure communication channel worse than leaving families without prompt reassurance or information?

Thankfully, the GMC guidance says that "you should use your judgment to apply these principles." That sounds sensible, but in an increasingly regulated landscape will our judgment always be supported?

Competing interests: See www.bmj.com/about-bmj/freelancecontributors/david-oliver.

Provenance and peer review: Commissioned; not externally peer reviewed.

1 General Medical Council. New confidentiality guidance published by the GMC. Jan 2017 http://www.gmc-uk.org/news/29299.asp.

2 Care Quality Commission. Safe data, safe care. Report into how data is safely and securely managed in the NHS. July 2016. https://www.cqc.org.uk/sites/default/files/20160701\% 20Data\%20security\%20review\%20FINAL\%20for\%20web.pdf.

3 NICE. Patient experience in adult NHS services. Quality statement 13: sharing information with partners, family members, and carers. https://www.nice.org.uk/guidance/qs15/chapter/ quality-statement-13-sharing-information-with-partners-family-members-and-carers

4 Department of Health. Confidentiality. NHS Code of Practice. https:/www.gov.uk/ government/uploads/system/uploads/attachment_data/file/200146/Confidentiality_-_NHS Code_of_Practice.pdf

5 Oliver D. Welcoming carers onto the ward. BMJ 2015;356:h4959.

Published by the BMJ Publishing Group Limited. For permission to use (where not already granted under a licence) please go to http://group.bmj.com/group/rights-licensing/ permissions 